AUOTORES

Globalize your Research

\section{Journal of Thoracic Disease and Cardiothoracic Surgery \\ Nightingale Syabbalo *}

\title{
Aerosol Biologics for the Treatment of Eosinophilic Asthma
}

\author{
Nightingale Syabbalo \\ Professor of Physiology and Medicine, Nabanji Medical Centre, P. O. Box 30243, Lusaka, ZAMBIA.
}

Corresponding Author: Nightingale Syabbalo, Professor of Physiology and Medicine, Nabanji Medical Centre, P. O. Box 30243, Lusaka, ZAMBIA.

Received date: December 25, 2021; Accepted date: January 07, 2021; Published date: January 15, 2022

Citation: Nightingale Syabbalo, (2022). Aerosol Biologics for the Treatment of Eosinophilic Asthma. J Thoracic Disease and Cardiothoracic Surgery, 3(1); DOI:10.31579/2693-2156/035

Copyright: ( ) 2022, Nightingale Syabbalo. This is an open access article distributed under the Creative Commons Attribution License, which permits unrestricted use, distribution, and reproduction in any medium, provided the original work is properly cited.

\begin{abstract}
Asthma is a heterogeneous chronic airway disease comprising of distinct phenotypes characterized by different immunopathophysiologic pathways, clinical features, disease severity, and response to treatment. The phenotypes of asthma include eosinophilic, neutrophilic, mixed cellularity, and paucigranulocytic asthma. Eosinophilic asthma is principally a T helper type 2 (Th2)-mediated airway disease. However, several other immune and structural cells secrete the cytokines implicated in the pathogenesis of eosinophilic asthma. Innate type 2 lymphoid cells, mast cells, basophils, and eosinophils secrete Th2 cytokines, such as interleukin-4 (IL-4), IL-13, and IL-5. Additionally, airway epithelial cells produce alarmin cytokines, including IL-25, IL-33, and thymic stromal lymphopoietin (TSLP). Alarmins are the key initiators of allergic inflammation at the sentinel mucosal surfaces. Innovative biotherapeutic research has led to the discovery of monoclonal antibodies which target and inhibit the immunopathological effects of the cytokines involved in the pathogenesis of eosinophilic asthma. Parenteral biologics targeting the inciting interleukins, include mepolizumab and reslizumab (anti-IL-5), benralizumab (anti-IL-5R $\alpha$ ), dupilumab (anti-4R $\alpha$ ), and tezelizumab (anti-TSLP). They have been shown to significantly reduce annualized exacerbation rates, improve asthma control, lung function, and quality of life. Currently, there are no pulmonary delivered aerosol biologics for topical treatment of asthma. CSJ117 is a potent neutralizing antibody Fab fragment against TSLP, formulated as a PulmoSol TM engineered powder, and is delivered to the lungs by a dry powder inhaler. Phase 2 placebo-controlled clinical trial evaluated the efficacy and safety of CSJ117. CSJ117 delivered as an inhaler attenuated the late asthmatic response (LAR), and the early asthmatic response (EAR) after allergen inhalation challenge (AIC) at day 84 of treatment. The maximum decrease in FVE1 from pre-AIC were significantly lower in the CSJ117 group compared to placebo $(\mathrm{P}=029)$, during LAR. CSJ117 also significantly reduced fractional exhaled nitric oxide before AIC at day 83; and significantly reduced the allergen-induced increase in $\%$ sputum eosinophil count. Pulmonary delivery of biologics directly to the airway mucosal surface has several advantages over parenteral routes, particularly in treating airway diseases such as asthma. Inhaler delivered biologics, such as CSJ117 are innovative and attractive methods of future precision treatment of asthma, and other respiratory diseases.
\end{abstract}

Keywords: eosinophilic asthma; interleukins; biologics; tezepelumab; CSJ117

\section{Introduction}

Asthma is a significant public health, and socio-economical problem affecting more than 358 million individuals worldwide [1]. It is a heterogeneous chronic airway disease encompassing distinct phenotypes characterized by different immunopathophysiological pathways, clinical features, disease severity, physiology, and response to treatment. The phenotypes of asthma include eosinophilic, neutrophilic, mixed cellularity, and paucigranulocytic asthma. Eosinophilic asthma is principally a T helper type 2 (Th2)-mediated disease. However, several other immune, such as innate type 2 lymphoid cells (ILC2s), mast cells, basophils, and eosinophils; and structural cells, including fibroblasts, myofibroblasts, and airway smooth muscle cells also secrete the cytokines, and chemokines implicated in the pathogenesis of eosinophilic asthma. Dysfunctional and injured airway epithelial cells exude a special type of cytokines termed alarmins, including IL-25, IL-33, and thymic stromal lymphopoietin (TSLP). Alarmins are the key initiators of allergic eosinophilic inflammation at the sentinel mucosal surfaces. Because there are several types of immune, and structural cells secreting cytokines promoting eosinophilic inflammation, eosinophilic asthma is also termed as Th2-high asthma, in contrast to Th2-low neutrophilic, and paucigranulocytic asthma.

Despite national guidelines [1-3], and innovative therapies, such as single dual inhaler or single triple inhaler therapy [4-7], about 3.6-10\% of the patients with asthma are unresponsive to the standard of care therapy [8- 
10]. Precise understanding of the pathophysiological mechanisms, and pathways involved in the pathogenesis of asthma has led to the innovate discovery of biologics for add-on treatment of severe, uncontrolled eosinophilic asthma.

A repertoire of biologics are currently available for the treatment of severe, uncontrolled eosinophilic asthma [11-15]. Parenteral administered biologics targeting the inciting interleukins in the pathogenesis of asthma, include omalizumab (anti-IgE), mepolizumab and reslizumab (anti-IL-5), benralizumab (anti-IL-5R $\alpha$ ), dupilumab (anti-4R $\alpha$ ), and tezelizumab (anti-TSLP). However, monoclonal antibodies (mAb) are less effective in the treatment of other phenotypes of asthma with low blood eosinophil

\begin{tabular}{|c|c|c|}
\hline Biologic & Dosage & Efficacy \\
\hline Omalizumab* & $75-375$ mg SC Q 2/4 wk & Reduces exacerbations (47-53\%) \\
\hline Mepolizumab* & 100 mg SC Q 4 wk & Reduces exacerbations (50-60\%) \\
\hline Reslizumab & $3 \mathrm{mg} / \mathrm{kg}$ IV Q 4 wk & Reduces exacerbations (34-75\%) \\
\hline Benralizumab* & 30 mg SC Q 8 wk & Reduces exacerbations (25-60\%) \\
\hline Dupilumab* & $300 \mathrm{mg}$ SC Q 2 wk & Reduces exacerbations (60-80\%) \\
\hline Tezepelumab* & 210 mg SC Q 4 wk & Reduces exacerbations (41-56\%) \\
\hline
\end{tabular}

Abbreviations: IV, intravenous, given over 25-50 min; SC, subcutaneous, Q, every; wk, weeks. * Approved for childhood asthma. Pediatric dosages depend on age and body weight of the child or adolescent.

Table 1: Dosages of approved biologics by the Food and Drug Administration for the treatment of severe asthma

\section{Results}

Airway epithelial cells play a key role in the regulation of tissue homeostasis by producing and secreting several proteins, such as antioxidants, lipid mediators, cytokines, chemokines, and growth factors $[24,25]$. Damaged, and dysfunctional epithelium produce large quantities of cytokines, and growth factors that interact with the underlying mesenchymal cells, including fibroblasts, and myofiblobasts to induce epithelial-mesenchymal transition (EMT), promote airway remodeling [26-28], resulting in persistent airway obstruction [26].

The epithelial-derived cytokines (also termed alarmins), such as interleukin-25 (IL-25) [29-31], IL-33 [31-34], and thymic stromal lymphopoietin (TSLP) [31,35-38] play an initiating key role in the pathogenesis of eosinophilic asthma. Alarmin cytokine secretion can be aroused by respiratory viral, bacterial, and fungal infections, allergens, proteases, chemical irritants, mechanical injury, and cytokines, such as TNF- $\alpha$, IL-1 $\beta[24,29]$. Epithelial-derived cytokines secretion during viral respiratory infections is the major trigger of asthma exacerbations, particularly in children $[39,40]$.

Biologics targeting alarmin cytokines have a potential to prevent, and efficaciously treat asthma, and exacerbations [41-45]. Inhibiting upstream alarmin cytokines by specific monoclonal antibodies is a very effective strategy capable of interfering with the downstream inflammatory cascades resulting in eosinophilic asthma $[41,46]$. Current biologics are not disease modifying, and discontinuing treatment with these biologics result in return of the severity of asthma to pre-treatment levels, or even worsening of asthma control [47,48]. Blocking alarmins, has the potential to inhibit EMT, airway hyperresponsiveness, and remodeling, thus preventing decline in lung function, and persistent severe eosinophilic asthma [42].

Currently, there are no biologics targeting IL-25, and IL-33 approved for the treatment of eosinophilic asthma. Itepekimab is a human IgG4P monoclonal antibody targeting IL-33. Wechsler et al. [49] have shown that a single subcutaneous injection of itepekimab $300 \mathrm{mg}$ reduces exacerbations, and improve asthma control, lung function (FEV1), and health-related quality of life (HLQoL). The efficacy of itepekimab was almost similar to that achieved by dupilumab, although the outcomes were slightly less. However, dual itepekimab plus dupilumab treatment did not counts, and low fractional exhaled nitric oxide (FeNO) levels, such as neutrophilic, and paucigranulocytic asthma [16-19]. Moreover, omalizumab [20], mepolizumab and benralizumab [21], and dupilumab $[22,23]$ therapies reduce exacerbations by about $50 \%$, and are unable to eliminate exacerbations completely. Discontinuation of the biologics may result in poor asthma control, and even worse symptoms, and frequent exacerbations. Thus, there is still unmet need to explore for novel biologics capable of treating most of the phenotypes of asthma, and to prevent airway remodeling, and fixed severe airflow limitation. (Table 1) depicts the dosages of the approved biologics for the treatment of severe eosinophilic asthma. 
Questionnaire-6 (ACQ-6), and the Asthma Quality of Life Questionnaire (AQLQ) scores [56]. This shows that tezepelumab is efficacious and safe for the treatment of adolescents and adults with severe, uncontrolled asthma.

Post-hoc analysis of phase 2b PATHWAY multicentre, randomized, double-blind, placebo-controlled study of 555 patients aged 18-75 years with severe, uncontrolled asthma with or without nasal polyps (NP) revealed that tezepelumab reduced AAER in both groups of patients [57]. Patients who received placebo with asthma and NP, and asthma without NP had higher AAER compared to those treated with tezepelumab [56]. The AAER was reduced to a similar extent in both groups of patients with asthma and NP, and asthma without NP who received tezepelumab 210 mg. The reduction in AAER for patients with asthma and NP was $75 \%$, and the reduction in AAER was $73 \%$ in patients with asthma without NP. In both groups of patients who received placebo, patients experienced one to three more exacerbations than in the tezepelumab $210 \mathrm{mg}$ group. Furthermore, treatment with tezepelumab $210 \mathrm{mg}$ resulted in decrease in blood eosinophil counts, and FeNO levels compared to placebo [57].

Exploratory analysis of the NAVIGATOR phase III trial has demonstrated that tezepelumab reduced exacerbations, and improved lung function; and nasal symptoms in patients with severe, uncontrolled asthma with nasal polyps [58]. Tezepelumab reduced AAER by $86 \%$ in patients with asthma and nasal polyposis, and by $52 \%$ in patients with asthma without nasal polyposis over 52 weeks, compared to placebo. Tezepelumab improved lung function at week 52 in both groups of patients with an increase in pre-bronchodilator FEV1 of $0.20 \mathrm{~L}$ in the patients with asthma and NP, and $0.13 \mathrm{~L}$ in patients with asthma without NP. Concomitantly, tezepelumab significantly improved symptoms of nasal polyps at week 52. It significantly reduced the SinoNasal Outcome Test (SNOT-22, [59]) scores in patients with asthma and nasal polyps by 9.6 points versus placebo. The adjusted mean scores reduction from baseline for tezepelumab was 20.10 points, and for placebo was 10.55 points. The baseline mean $( \pm \mathrm{sd})$ SNOT-22 scores for tezepelumab was $49.4 \pm 21.5$, and for placebo was $47.8 \pm 19.0$ [56]. Thus, demonstrating that tezepelumab may also be effective in the treatment of chronic rhinosinusitis with nasal polyps (CRSwNP) [58]. Tezepelumab is in phase 3 clinical trials for the treatment of CRSwNP.

The results from the NAVIGATOR trial exploratory analysis are exciting [58]. Patients with eosinophilic asthma and comorbid chronic rhinosinusitis with nasal polyps have more severe united airway disease than patients with eosinophilic asthma or CRSwNP alone [57,60]. Asthmatic patients with CRSwNP experience frequent exacerbations, hospitalization, emergency department visits; and have poor lung function, and HLQoL [61,62]. On the other hand, patients with CRSwNP and asthma have persistent severe nasal obstruction, hyposmia, sleep disturbance, anxiety, and depression, and worse HLQoL [63-65]. They are often corticosteroid dependent, and require frequent functional endoscopic nasal surgery for nasal polyps $[66,67]$.

Treatment of severe eosinophilic asthma with comorbid CRSwNP is challenging. Such patients require a universal targeted therapy, such as biologics, and in particular biologics delivered directly to the nasal airways, and tracheobronchial tree. Currently, there are no approved intranasal or inhaler biologics for the treatment of eosinophilic asthma, and CRSwNP. Noteworthy, dupilumab [68], and omalizumab [69] which are administered subcutaneously are approved for the treatment of both eosinophilic asthma, and CRSwNP.

\section{Discussion}

\section{Pulmonary Delivery of Aerosol Biologics}

Biological drugs (synonymous known as biologics) are a diverse group of therapeutic agents which are large and complex molecules produced through sophisticated biotechnology [70, 72]. The biologics currently used to treat severe asthma are monoclonal antibodies, and antibody fragments, which are administered subcutaneously, or intravenously (reslizumab). Injection of drugs is painful and inconvenient, especially when the drugs are for the treatment of chronic diseases, such as asthma, and alpha- 1 antitrypsin deficiency $[73,74]$. Moreover, $10 \%$ of the patients worldwide suffer from needle phobia leading to poor compliance [75]. Pulmonary delivery of biologics to the lungs improve pharmacokinetics, and toxicity profiles of proteins. It is a non-invasive route, and allows for self-administration, which could improve patient compliance [76].

Pulmonary delivery of biologics is an attractive non-invasive route of administration for the treatment of respiratory diseases [76-79], such as asthma [80-84], cystic fibrosis [85, 86], alpha-1 antitrypsin deficiency (AATP) [87,88], pulmonary alveolar proteinosis (PAP) [89,90], lung cancer [91,92], and SARS-CoV-2 [93-95]. Pulmonary delivery of biologics is also an alternative route for administering biologics for the treatment of non-respiratory systemic diseases, including diabetes mellitus [96-98], anaemia [99], and multiple sclerosis [100]. The development of inhalation biologics, and design of methods of inhalation technology are outside the scope of this manuscript, but excellent information can be found in references [76-79]. Table 2 shows preclinical trials of aerosol biologics for the treatment of respiratory diseases, and non-respiratory systemic diseases.

\begin{tabular}{|l|}
\hline Alpha-1 anti-trypsin deficiency (AATP) \\
Pulmonary alveolar proteinosis (PAP) \\
Cystic fibrosis \\
Bronchiectasis \\
Bronchiolitis obliterans organizing pneumonia (BOOP) \\
Asthma \\
Chronic obstructive pulmonary disease (COPD) \\
Acute aplastic bronchitis \\
Pulmonary hypertension \\
Respiratory viral infections (RSV, Parainfluenza) \\
Pneumonia (Pseudomonas aeroginosa) \\
Tuberculosis \\
Non-tuberculous mycobacterial infection \\
Acute lung injury (ALI) \\
Acute respiratory distress syndrome (ARDS) \\
Respiratory viral infections (RSV, influenza) \\
SARS-CoV-2 \\
Lung cancer, lung metastasis
\end{tabular}


Diabetes mellitus

Multiple sclerosis

Anaemia

Infertility

Table 2: Preclinical trials of aerosol biologics in respiratory diseases, and non-respiratory systemic diseases

The large surface area, and the extensive vascularization of the airways, and lungs enable rapid absorption, and fast onset of action of drugs delivered to the lungs [101]. Pulmonary delivery also offers the advantage of delivering biologics at high concentration in the lungs, and directly to inflammatory cells, and has the potential to achieve high blood levels of the biologics. Additionally, there is a lower level of proteolytic enzymatic activity in the lung, and minimal first-pass metabolism [76], hence higher concentrations of the biologics in the airways, and lung parenchyma.

However, despite the beneficial effects of pulmonary delivery of biologics, it requires innovative biotechnology to develop biologics, and inhaler devices to propel the biologics to the tracheobronchial tree, and lung parenchyma [76-79]. Furthermore, there are anatomical, physiological, and immunological factors that affect the pharmacodynamics, and biotherapeutic efficacy, and safety of inhaled biologics [102]. The other obstacle is the formulation of biologics for delivery into the lungs $[78,79,103]$. Three methods have been applied to modify the structure, aerodynamic diameter (Dae), shape, hydroscopicity, and density of biologics to enhance their absorption through the mucociliary blanket, pharmacokinetics, and bioavailability [104,105]. They include antibody fragment development [106,107], Fc engineering $[108,109]$, and pegylation $[110,111]$. Pegylation protects proteins from renal clearance and proteolytic degradation, thus prolongs protein local residence time, and bioavailability in the body [110]. Pegylation has been shown to be an effective method for extending the retention time of biologics in the lung, such as human alpha-1 proteinase inhibitor ( $\alpha 1-\mathrm{PI})$ [112], IFN- $\alpha$ [113], and antibody fragments [114,115].

The type of inhaler has critical importance for the delivery of biologics, because $75 \%$ of inhaled protein formulations in clinical research are produced as liquids [76]. There are four main types of inhalers for the delivery of orally inhaled proteins, peptides, and cytokines, such as pressure metered dose inhalers (PMDI), dry powder inhalers (DPI), soft mist inhalers (SMI), and nebulizers [77,79,116-120].

Most biologics in clinical trial for the treatment of asthma have been delivered to the lung by DPIs. However, SMIs are novel multidose propellant-free, handheld inhalers, and are more suitable for delivery of biologics than pMDI [79]. The most experience of pulmonary delivery of biologics with DPIs has been the Exubera ${ }^{\circledR}$ and Technosphere ${ }^{\circledR}$ insulin (Afrezza ${ }^{\circledR)}$, for the treatment of diabetes mellitus [121]. Currently, three DPIs have been utilized in clinical trials for the delivery of biologics to the lungs. They include the F1P for administration of the anti-IL-13 monoclonal antibody fragment VR942 (Abrezekimab) [102]; Cyclohaler ${ }^{\circledR}$ (single dose, PB Pharma GmbH, Meerbusch, German) for the administration of DAS181 (Fludase $\left.{ }^{\circledR}\right)$ [122]; and Concept1 (single dose, Norvatis, Basel, Switzerland) (NCT4410523) for administration of the anti-thymic stromal lymphopoietin monoclonal antibody Fab fragment CSJ117 [84,123]. Biotechnological modification of proteins and peptides, and proper inhaler devices can be successfully used to deliver biologics which are effective, and immunologically safe for the treatment of airway diseases, pulmonary diseases, and systemic diseases.

The precise mechanism by which mAb, and antibody fragments exert their immunotherapeutic effects is by inhibiting surface receptors on immune and inflammatory, and immune cells, thus preventing these cells from secreting cytokines, chemokines, and adhesion molecules. Several $\mathrm{mAb}$, and antibody fragments are currently in preclinical and clinical trials for the treatment of eosinophilic asthma [81-83,120,122-126], and neutrophilic asthma [127]. However, CSJ117 has demonstrated very encouraging and promising results.

\section{Csj117 Dpi for the Treatment of Eosinophilic Asthma}

CSJ117 is a potent neutralizing antibody Fab fragment against TSLP. It is formulated as a PulmoSol ${ }^{\mathrm{TM}}$ engineered powder in hard capsules for delivery to the lungs by a dry powder inhale (DPI). Phase 2 double-blind, placebo-controlled clinical trial evaluated the efficacy and safety of CSJ117 on the late asthmatic response (LAR), the early asthmatic response (EAR), and biomarkers of eosinophilic asthma after allergen inhalation challenge (AIC) $[84,128]$. CSJ117 significantly attenuated the LAR and EAR at day 84 of treatment. The maximum decrease in FVE1 from pre-AIC were significantly lower in the CSJ117 group compared to placebo $(\mathrm{P}=029)$, during LAR. CSJ117 also significantly reduced fractional exhaled nitric oxide before AIC at day 83; and significantly reduced the allergen-induced increase in \% sputum eosinophil count [84]. This study demonstrates the potential of inhaled biologics, particularly those targeting the alarmin cytokines in the treatment and prevention of eosinophilic asthma. Aerosol CSJ117 by acting topically and blocking the immunopathological effects of TSLP may become the precise asthmatic drug delivery in the nearby future.

\section{Conclusion}

Eosinophilic asthma is principally a Th2-mediated airway disease. Th2 lymphocytes, ILCs, mast cells, and eosinophils secrete inflammatory cytokines, such as IL-4, IL-13, and IL-5 which promote airway inflammation, AHR, and remodeling. Additionally, dysfunctional epithelial cells exude alarmin cytokines, including IL-25, IL-33, and TSLP which further amplifies the inflammatory cascade, and airway remodeling. Patients with eosinophilic asthma respond favourably to targeted mAb, such as omalizumab, mepolizumab, dupilumab, and tezepelumab. However, biologics do not modify progressive airway remodeling which is responsible for severe asthma. Conventionally, asthma is best treated with locally-acting aerosol inhalers, such as LABA, ICS, and single triple inhaler therapy. Currently, there are no aerosol biologics for the treatment of asthma. CSJ117 is a potent neutralizing antibody Fab fragment against TSLP, formulated as a PulmoSol TM engineered powder, and is delivered to the lungs by a dry powder inhaler. CSJ117 delivered as an inhaler has been shown to attenuate the late asthmatic response, and the early asthmatic response after allergen inhalation challenge at day 84 of the treatment. CSJ11 significantly improved pre-AIC lung function (FEV1) compared to placebo. Additionally, CSJ117 significantly decreased inflammatory biomarkers of eosinophilc asthma, such as allergen-induced increase in \% sputum eosinophil count, and FeNO. Pulmonary delivery of aerosol biologics to the lungs is a precise targeted route of drug administration to treat patients with eosinophilic asthma.

\section{Conflict of interest:}

The author declares that the publication was conducted in the absence of any commercial or financial relationships that could be construed as a potential conflict of interest.

\section{Abbreviations}

AAER: Annualized asthma exacerbation rates 
AATP: Alpha-1 anti-trypsin deficiency

ACQ-6: Asthma Control Questionnaire-6

AHR: Airway hyperresponsiveness

AIC: Allergen inhalation challenge

ALI: Acute lung injury

AQLQ: Asthma Quality of Life Questionnaire

ARDS: Acute respiratory distress syndrome

BOOP: Bronchiolitis obliterans organizing pneumonia

COPD: Chronic obstructive pulmonary disease

COVID-19: Coronavirus Disease 19

CRSwNP: Chronic rhinosinusitis with nasal polyps

Dae: Aerodynamic diameter

DPI: Dry powder inhaler

AER: Early asthmatic response

EMT: Epithelial-mesenchymal transition

FeNO: Fractional exhaled nitric oxide

FEV1: forced expired volume in one second

HLQoL: Health-related quality of life

ICS: Inhaled Corticosteroid

IgE: Immunoglobulin E

IL: Interleukin

ILCs: Innate type 2 lymphoid cells

LABA: Long-acting beta-2 agonist

LAR: Late asthmatic response

mAb: monoclonal antibody

OCS: Oral Corticosteroid

PAP: Pulmonary alveolar proteinosis

PMDI: Pressure metered dose inhaler

RSV: Respiratory syncytial virus

SARS-CoV-2: Severe acute respiratory syndrome coronavirus 2

SNOT-22: SinoNasal Outcome Test 22

Th2: T helper type 2 lymphocytes

TNF- $\alpha$ : Tumor necrosis factor- $\alpha$

TSLP, thymic stromal lymphopoietin

\section{References}

1. Global Initiative for Asthma. (2020) Global Strategy for Asthma Management and Prevention. - updated 2020.

2. Cloutier MM, Baptist AP, Blake KV, et al. (2020) Expert Panel Working Group of the National Heart, Lung, and Blood Institute. 2020 Focused updates to the asthma management guidelines: a report from the National Asthma Educational and Preventive Program Coordinating Committee Expert Panel Working Group. J Allergy Clin Immunol 146(6):1217-1270.

3. Cloutier MM, Dixon AE, Krishnan JA, Lemanske RF Jr, Pace W, Schatz M. (2020) Managing asthma in adolescents and adults: 2020 asthma guideline update from the National Asthma Education and Prevention Program. JAMA 324(22):2301-2317.

4. Virchow JC, Kuna P, Paggiaro P, Papi A, Singh D, Corre S, et al. Single inhaler extrafine triple therapy in uncontrolled asthma (TRIMARAN and TRIGGER): two double-blind, parallel-group, randomised, controlled phase 3 trials. Lancet 394(10 210): 1737-1749.

5. Singh D, Cruz AA, Canonica GW, Vele A, Kots M, Georges G, Papi A. Extrafine triple therapy in patients with asthma and persistent airflow limitation. Eur Respir J 2020; 56:2000476;

6. Lee LA, Bailes Z, Barnes N, Boulet L-P, Edwards D, Fowler A, Hanania N, Kerstjens HB, et al. (2020) Efficacy and safety once-daily single-inhaler triple therapy (FF/UMEC/VI versus FF/VI in patients with inadequately controlled asthma (CAPTAIN): a double-blind, randomised, phase 3A trial. Lancet Respir Med.

7. Kim LHY, Saleh C, Whalen-Browne A, et al. (2021) Triple vs dual inhaler therapy and asthma outcomes in moderate to severe asthma: a systematic review and meta-analysis. JAMA

8. Holgate ST, Polosa R. (2006) The mechanisms, diagnosis, and management of severe asthma in adults. Lancet 368:780-793.

9. Moore WC, Bleecker ER, Curran-Everett D, Erzurum SC, Ameredes BT, Bacharier L, et al. (2007) National Heart, Lung, Blood Institute's Severe Asthma Program. Characterization of the severe asthma phenotype by the National Heart, Lung, and Blood Institute's Severe Asthma Research Program. J Allergy Clin Immunol 119:405-413.

10. Peters MC, Kerr S, Duncan EM, Woodruff PG, Fajt ML, Levy BD, Israel E, Phillips BR, et al; National Lung and Blood Institute Severe Asthma Research Program-3. Refractory airway type-2 inflammation in a large subgroup of asthmatics treated with inhaled corticosteroids. J Allergy Clin Immunol 2018; pii: S0091-6749(18)30390-7.

11. McCracken J, Tripple J, Calhourn WJ. (2016) Biologic therapy in the management of asthma. Curr Opin Allergy Clin Immunol 16(4):375-382.

12. Pepper AN, Renz H, Casale TB, Garn H. (2017) Biologic therapy and novel molecular targets of severe asthma. J Allergy Clin Immunol 5:909-915. DOI:

13. McGregor MC, Krings JG, Nair P, Castro M. Role of biologics in asthma. (2019) Am J Respir Crit Care Med 199(4):433-445.

14. Syabbalo N. (2021) Biologics for the treatment of severe childhood asthma. J Thorac Dis Cardiothorac Surg 2(2); 31579/2693-2156/024.

15. Hanania NA, Wenzel S, Rosen K, Hsieh HJ, Mosesova S, Choy DF, Lal P, Arron JR, Harris JM, Busse W. (2013) Exploring the effects of omalizumab in allergic asthma: an analysis of biomarkers in the EXTRA study. Am J Respir Crit Care Med 187:804-811.

16. Busse WW, Bleecker ER, FitzGerald JM,Bora study investigators. (2019) Long-term safety and efficacy of benralizumab in patients with severe, uncontrolled asthma: 1 -year results from the BORA phase 3 extension trial. Lancet Respir Med 7:46-59.

17. Castro M, Corren J, Pavord ID, Maspero J, Wenzel S, Rabe KF, Busse WW, Ford L, Sher L, FitzGerald JM, et al. (2018) Dupilumab efficacy and safety in moderate-tosevere uncontrolled asthma. N Engl J Med 378:486-496.

18. Syabbalo N. (2020) Clinical features and management of paucigranulocytic asthma. Ann Clin Med Res 1(3): 1011.

19. Normansell R, Walker S, Milan SJ, Walters EH, Nair P. (2014) Omalizumab for asthma in adults and children. Cochrane Database Syst Rev (1):CD003559.

20. Farne HA, Wilson A, Powell C, Bax L, Milan SJ. (2017) Anti-IL5 therapies for asthma. Cochrane Database Syst Rev 9:CD010834.

21. Zayed Y, Kheiri B, Banifadel M, Hicks M, Aburahma A, Hamid K, Bachuwa G, Chandran A. (2018) Dupilumab safety and efficacy in uncontrolled asthma: a systematic review and meta-analysis of randomized clinical trials. J Asthma 56:1-10.

22. Xiong XF, Zhu M, Wu HX, Fan LL, Cheng DY. (2019) Efficacy and safety of dupilumab for the treatment of uncontrolled asthma: a meta-analysis of randomized clinical trials. Respir Res 20:108. 
23. Bartemes KR, Kita H. (2012) Dynamic role of epitheliumderived cytokines in asthma. Clin Immunol 143(3):222235.

24. Syabbalo N. (2020) Airway epithelial dysfunction contributes to the pathogenesis of asthma. J Lung Pulmonol Respir Res 7(4):101-105.

25. Holgate ST, Holloway J, Wilson S, Bucchieri F, Puddicombe S, Davis DE. (2004) Epithelial mesenchymal communication in pathogenesis of chronic asthma. Proc Am Thorac Soc 1(2):93-98.

26. Hackett T-L, Warner SM, Sefanowicz D, Shaheen F, Pechkovsky DV, Murray LA, Argentieri R, et al. (2009) Induction of epithelial-mesenchymal transition in primary airway epithelial cells from patients with asthma by transforming growth factor- $\beta 1$. Am J Respir Crit Care Med 180(2):122-133.

27. Hacket T-L. Epithelial-mesenchymal transition in the pathophysiology of airway remodeling in asthma. Curr Opin Immunol 2012; 12(1):53-59.

28. Mitchell PD, O'Byrne PM, Epithelial derived cytokines in asthma. Chest 2017; 151(6):1338-1344.

29. Roan F, Obata-Ninomiya K, Ziegler SF. (2019) Epithelialderived cytokines: More than just signaling the alarm. J Clin Investig 129:1441-1451.

30. Hong H, Liao S, Chen F, Yang Q, Wang DY. Role of IL25, IL-33, and TSLP in triggering united airway diseases toward type 2 inflammation. Allergy 2020; 75:2794-2804.

31. Cherry WB, Yoon J, Bartemes KR, Iijima K, Kita A. (2008) A novel IL-1 family cytokine, IL-33, potentially activates human eosinophils. J Allergy Clin Immunol 121:14841490.

32. Louten J, Rankin AL, Li Y, Murphy EE, Beaumont M, Moon C, et al. (2011) Endogenous IL-33 enhances Th2 cytokine production and T-cell responses during allergic airway inflammation. Int Immunol 23:307-315.

33. Cayrol C, Girard JP. IL-33: (2012) an alarmin cytokine with crucial roles in innate immunity, inflammation and allergy 2014; 31:31-37.

34. Zhang Y, Zhou B. (2012) Functions of thymic stromal lymphopoietin in immunity and disease. Immunol Res 52(3):211-223.

35. Watson B, Gauvreau GM. (2014) Thymic stromal lymphopoietin: a central regulator of allergic asthma. Expert Opin Ther Targets 18(7):771-785.

36. Ziegler SF, Roan F, Bell BD, Stoklasek TA, Kitajima M, Han H. (2013) The biology of thymic stromal lymphopoietin (TSLP). Adv Pharmacol 66:129-155. Adhikary PP, Tan Z, Page BDG, Hedtrich S. (2021) TSLP as a druggable target-A silver-lining for atopic diseases? Pharmacol ther 217:107648.

37. Johnston SL, Pattemore PK, Sanderson G, et al. (1995) Community study of role of viral infections in exacerbations of asthma in 9-11 year old children. BMJ 310:1225-1229.

38. Busse WW, Lemanske RF Jr, Gern JE. (2010) Role of viral respiratory infections in asthma and asthma exacerbations. Lancet 376(9743):826-834. DOI:.

39. Pelaia C, Pelaia G, Longhini F, Crimi C, Calabrese C, Gallelli L, Sciacqua A, Vatrella A. (2021) Monoclonal antibodies targeting alarmins: a new perspective for biological therapies of severe asthma. Biomedicines 9(9):

40. Gauvreau GM, White L, Davis BE. (2020) Anti-alarmins entering clinical trials. Curr Opin Pulm Med 26:69-76. Porsbjerg CM, Sverrild A, Lloyd CM, Menzies-Gow AN,
Bel EH. (2020) Anti-alarmins in asthma: Targeting the airway epithelium with next generation biologics. Eur Respir J 56:2000260.

41. Pelaia C, Crimi C, Vatrella A, Tinello C, Terracciano R, Pelaia G. (2020) Molecular targets for biological therapies of severe asthma. Front Immunol 11:603312.

42. Albrecht M. (2021) Targeting alarmins and other epithelial mediators of allergic inflammation with biologics. Allergol Select 5:82-88.

43. Syabbalo N. (2020) Targeting alarmin cytokines in the treatment of asthma. J Pulm Med 4:5. Editorial.

44. Ortega H, Lemiere C, Llanos JP, et al. (2019) Outcomes following mepolizumab treatment discontinuation: realworld experience from an open-label trial. Allergy Asthma Clin Immunol 15:37.

45. Haldar P, Brightling CE, Singapuri A, et al. (2014) Outcomes after cessation of mepolizumab therapy in severe eosinophilic asthma: a 12-month follow-up analysis. J Allergy Clin Immunol 133:921-923.

46. Wechsler ME, Ruddy MK, Pavord ID, Isreal E, Rabe KF, Ford LB, Maspero JF, Abdulai RM, Hu C-C, et al. (2021) Efficacy and safety of itekepemab in patients with moderate-to-severe asthma. N Engl J Med 385:1656-1668.

47. Verstraete K, Peelman F, Braun H, Lopez J, Van Rompaey D, Dansercoer A, Vandenberghe I, Pauwels K, Tavernier J, Lambrecht BN, et al. (2017) Structure and antagonism of the receptor complex mediated by human TSLP in allergy and asthma. Nat Commun 8:14937.

48. Matera MG, Rogliani P, Calzetta L, Cazzola M. (2020) TSLP inhibitors for asthma: current status and future prospects. Drugs 80:449-459.

49. Corren J, Parnes JR, Wang L, Mo M, Roseti SL, Griffiths JM, et al. (2017) Tezepelumab in adults with uncontrolled asthma. N Engl J Med 377:936-946.

50. Corren J, Garcia GE, Parnes JR, Pham TH, Griffiths JM. (2019) Tezepelumab treatment effect on annualized rate of exacerbations by baseline biomarkers in uncontrolled severe asthma patients: phase 2b PATHWAY study. Am J Respir Crit Care Med 199:A2621.

51. Pham T-H, Ren P, Parnes JR, Griffiths JM. (2019) Tezepelumab reduces multiple key inflammatory biomarkers in patients with severe, uncontrolled asthma in the phase 2b PATHWAY study. Am J Respir Crit Care Med 199:A2677.

52. AstraZeneca, Tezepelumab granted Breakthrough Therapy Designation by US FDA.[https://www.astrazeneca.com/media-centre/pressreleases/2018/tezepelumab-granted-breakthrough-therapydesignation-by-us-fda-07092018.html].

53. Menzies-Gow, Corren J, Bourdin A, Chupp G, Israel E, Wechsler ME, Brightling CE, Griffiths JM, et al. (2021) Tezepelumab in adults and adolescents with severe, uncontrolled asthma. $\mathrm{N}$ Engl J Med DOI: 10.1056/NEJMoa2034975.

54. Emson C, Corren J, Salapa K, Hellquist A, Parnes JR, Colice G. (2021) Efficacy of tezepelumab in patients with severe, uncontrolled asthma with or without polyps: a posthoc analysis of the phase $2 \mathrm{~b}$ PATHWAT study. J Asthma 14:91-99.

55. Menzies-Gow A, et al. (2021) Tezepelumab efficacy in patients with severe, uncontrolled asthma and comorbid nasal polyps in NAVIGATOR. ERS poster number: PA876. Poster presentation at the European Respiratory Society 
(ERS) International Congress 5 September 13:15-14:15 CEST.

56. Hopkins C. (2009) Psychometric validity of the 22-item Sinonasal Outcome Test. Clinical Otolaryngology 34:447454.

57. Bilodeau L, Boulay ME, Prince P, Boisvert P, Boulet LP. (2010) Comparative clinical and airway inflammatory features of asthmatics with or without polyps. Rhinology 48(4):420-425.

58. ten Brinke, Grootendorst DC, Schmidt JT, et al. (2002) Chronic sinusitis in severe asthma is related to sputum eosinophilia. J Allergy Clin Immunol 109: 621-626.

59. Syabbalo N. (2020) Clinical features and management of eosinophilic asthma. J Respir Dis Treat 1:105.

60. Halawi AM, Smith SS, Chandra RK. Chronic rhinosinusitis: epidemiology and cost. Allergy asthma Proc 2013; 34:328-334.

61. Stevens WW, Schleimer RP. Chronic rhinosinusitis with nasal polyps. J Allergy Clin Immunol 2016; 4(4):565572.

62. Hopkins C. (2019) Chronic rhinosinusitis with nasal polyps. N Engl J Med 381:55-63.

63. Mendelsohn D, Jeremic G, Wright ED, Rotenberg BW. (2011) Revision rates after endoscopic sinus surgery: a recurrence analysis. An Otol Rhinol Laryngol 120:162-166.

64. Smith KA, Orlandi RR, Oakley G, Meeks H, Curtin K, Alt JA. (2019) Long-term revision rates for endoscopic sinus surgery. Int Forum Allergy Rhinol 9:402-408.

65. Bachert C, Han JK, Desrosiers M, et al. Efficacy and safety of dupilumab in patients with severe chronic rhinosinusitis with nasal polyps (LIBERTY NP SINUS-24 and LIBERTY NP SINUS-52): results from two multicentre, randomized, double-blind, placebo-controlled, parallel-group phase 3 trials. Lancet 2019; 394:1634-1650..

66. Gevaert P, Omachi PA, Corren J, Han J, Lee S, Kafman D, Ligueros-Saylan M, Howard M, et al. Efficacy and safety of omalizumab in nasal polyposis: 2 randomized phase 3 trials. J Allergy Clin Immunol 2020; 146(3):595-605.

67. Zelikin AN, Healy CEAM. (2016) Materials and methods for delivery of biological drugs. Nat Chem 8:997-1007.

68. Durán-Lobato M, Niu Z, Alonso MJJAM. Oral delivery of biologics for precision medicine. Adv Mater 2020; 32:1901935.

69. Chung SW, Hil-Lal TA, Byun Y. (2012) Strategies for noninvasive delivery of biologics. J Drug Target 20:481-501.

70. Griese M, Scheuch G. (2016) Delivery of Alpha-1 Antitrypsin to Airways. Ann Am Thorac Soc 13:S346S351.

71. Osman N, Kaneko K, Carini V, Saleem I. (2018) Carriers for the targeted delivery of aerosolized macromolecules for pulmonary pathologies. Expert Opin Drug Deliv 15(8):821834.

72. Sokolowski CJ, Giovannitti JA, Boynes SG. (2010) Needle Phobia: Etiology, Adverse Consequences, and Patient Management. Dent Clin 54:731-744.

73. Bodier-Montagutelli E, Mayor A, Vecellio L, Respaud R, Heuzé-Vourc'h N. (2018) Designing inhaled protein therapeutics for topical lung delivery: what are the next steps? Expert Opin Drug Del 15(8):729-736.

74. Mathews A, Ee PLR, Ge R. (2020) Developing inhaled protein therapeutics for lung diseases. Mol Biomed 1(1):11.

75. Fröhlich F, Salar-Behzadi S, et al. (2021) Oral inhalation for delivery of proteins and peptides to the lung. Eur $\mathbf{J}$ Pharmaceutics Biopharmaceutics 163:198-211. Liang W, Pan HW, Vllasaliu D, Lam JKW. (2020) Pulmonary delivery of biological drugs: Pharmaceutics 12:1025. doi: 10.3390/pharmaceutics12111025.

76. Hacha J, Cataldo DD. (2012) Nebulized anti-IL-13 monoclonal antibody Fab0 fragment reduces allergeninduced asthma. Am J Respir Cell Mol Biol 47:709-717.

77. Gozzard N, Lightwood D, Tservistas M, Zehentleitner M, Sarkar K, Turner A, Smith B, Lamour SD, Bourne T, Shaw $S$, et al. (2017) Novel inhaled delivery of anti-IL-13 MAb (Fab fragment): Preclinical efficacy in allergic asthma. In Proceedings of the European Respiratory Society Annual Congress, Milan, Italy, 9-13

78. Bruns I, Fitzgerald M, Mensing G, Tsung M, Pardali K, Gardiner P, Keeling D, Axelsson L, Olsson M, et al. (2019) Late Breaking Abstract - Multiple ascending dose study of inhaled IL-4Ra antagonist, AZ1402/PRS-060, in mild asthmatics demonstrates robust FeNO reduction and a promising clinical profile for the treatment of asthma. Eur Respir J PA3709. 10.1183/13993003.congress2019.PA3709.

79. Faghihi H, Najafabadi AR, Daman Z, Ghasemian E, Montazeri H, Vatanara A. (2019) Respiratory administration of Infliximab powder for local suppression of inflammation. AAPS PharmSciTech 20:128. 10.1208/s12249-019-1308-0.

80. Gauvreau G, Hohlfeld J, Grant S, Jain M, Cabanski M, Pertel P, Boulet L-P, Cockcroft D, Davis B, Fitzgerald J, et al. (2020) Efficacy and safety of an inhaled anti-TSLP antibody fragment in adults with mild atopic asthma. Am J Respir Crit Care Med 201:A4207. doi: 10.11.1164/ajrccmconference.2020.201.1_MeetingAbstracts.A4207.

81. Kerem E, Blau H, Shteinberg M, et al. (2017) WS01.2 phase II clinical trial results of alidornase for the treatment of cystic fibrosis. J Cystic Fibros 16:S1-S16.

82. Nanus M. (2017) Protalix BioTherapeutics announces phase II clinical trial results for alidornase alfa in cystic fibrosis presented at the 40th European Cystic Fibrosis Society Conference. Protalix BioTherapeutics. Published.

83. Sorrells S, Camprubi S, Griffin R, Chen J, Ayguasanova J. (2015) SPARTA clinical trial design: Exploring the efficacy and safety of two dose regimens of alpha 1-proteinase inhibitor augmentation therapy in alpha 1-antitrypsin deficiency. Respir Med 109:490-499.

84. Strnad P, McElvaney NG, Lomas DA. (2020) Alpha 1Antitrypsin Deficiency. N Engl J Med 382:1443-1455.

85. Campo I, Mariani Fet al. (2016) Inhaled sargramostim and whole lung lavage (WLL) as therapy of autoimmune pulmonary alveolar proteinosis (aPAP). Eur Respir J 48:PA3870. 10.1183/13993003.congress-2016.PA3870.

86. Tazawa R, Ueda M, Abe M, Tatsumi K, Eda R, Kondoh S, Morimoto K, Tanaka E, Yamaguchi E, Takahashi A, et al. (2019) Inhaled GM-CSF for pulmonary alveolar proteinosis. N Engl J Med 381:923-932. 10.1056/NEJMoa1816216.

87. Maillet A, Guilleminault L, Legrain B, et al. (2011) The airways: a novel route for delivering monoclonal antibodies to treat lung tumors. Pharm Res 28:2147-2156.

88. Guilleminault L, Azzopradi N, et al. (2014) Fate of inhaled monoclonal antibodies after deposition of aerosolized particles in the respiratory system. J Control Release 196:344-354.

89. Hanke L, Perez LV, Sheward DJ, Das H, Schulte T, Moliner-Morro A, Corcoran M, Achour A, Hedestam GBK, Hallberg BM, et al. An alpaca nanobody neutralizes SARS$\mathrm{CoV}-2$ by blocking receptor interaction. Nat Commun. 
90. Konwarh R. Nanobodies: Prospects of Expanding Gamut of Neutralizing Antibodies Against the Novel Coronavirus, SARS-CoV-2. Front Immunol 2020; 11:1531.

91. BioSpace. (2020) Ansun Biopharma enrols first patient in proof of concept trial of DAS181 for the treatment of COVID-19.

92. White S, Bennett DB, Cheu S. (2005) Exuberafi: Pharmaceutical Developmant of a Novel Product for Pulmonary Delivery of Insulin. Diabetes Technol Ther 7:896-906.

93. Cassidy JP, Amin N, Marino M, Gotfried M, Meyer T, Sommerer K, Baughman RA. (2011) Insulin Lung Deposition and Clearance Following TechnospherefiInsulin Inhalataion powder Administration. Pharm Res 28:21572164.

94. Klonoff DC. Afrezza inhaled insulin: The fastest-acting FDA-approved insulin on the market has favourable properties. J Diabetes Sci Technol 2014; 8:1071-1073.

95. Dumont JA, Bitonti AJ, Clark D, Evans S, Pickford M, Newman SP. Delivery of an Erythropoietin-Fc Fusion Protein by Inhalation in Humans through an Immunoglobulin Transport Pathway. J Aerosol Med 2005; 18:294-3003.

96. Vallee S, Rakhe S, Reidy T, Walker S, Lu Q, Sakorafas P, Low S, Bitonti A. (2012) Pulmonary Administration of Interferon Beta-1a-Fc Fusion Protein in Non-Human Primates Using an Immunoglobulin Transport pathway. J Interf Cytokine Res 32:178-184.

97. Agu R, Ugwoke MI; Armand M, Kinget R, Verbeke N. (2001) The lung as a route for systemic delivery of therapeutic proteins and peptides. Respir Res 2:198-209.

98. Burgess G, Boyce M, Jones M, Larsson L, Main MJ, Morgan F, Phillips P, Scrimgeour A, Strimenopoulou F, Vajjah P, et al. (2018) Randomized study of the safety and pharmacodynamics of inhaled interleukin-13 monoclonal antibody fragment VR942. EBioMedicine 35:67-75.

99. Pilcer G, Amighi K. (2010) Formulation strategy and use of excipients in pulmonary drug delivery. Int J Pharm 392:119.

100. Carvalho TC, Peters JI, Williams RO, III. Influence of particle size on regional lung deposition - What evidence is there. Int J Pharm 2011; 406:1-10.

101. Ibrahim M, Verma R, Garcia-Contreras L. (2015) Inhalation drug delivery devices: technology update. Med Devices 8:131-139.

102. Jones RGA, Landon J. (2003) A protocol for 'enhanced pepsin digestion': A step by step method for obtaining pure antibody fragments in high yield from serum. J Immunol Methods 275:230-250.

103. Ma H, O'Kennedy R. Recombinant antibody fragment production. Methods 2017; 116:23-33.

104. Spiekerman GM, Finn PW, Ward ES, Dumont J, Dickison BL, Blumberg RS, Lencer WI. Receptor-mediated immunoglobulin $\mathrm{G}$ transport across mucosal barriers in adult life: Functional expression of FCRn in the mammalian lung. J Exp Med 2002; 196:303:310.

105. Bitonti AJ, Dumont JA, Low SC, Peters RT, Kropp KE, Palombella VJ, Stattel JM, Lu Y, Tan CA, Song JJ, et al. Pulmonary delivery of an erythropoietin Fc fusion protein in non-human primates through an immunoglobulin transport pathway. Proc Natl Acad Sci USA 2004; 101:9763-9768.

106. Harris JM. Chess RB. Effect of pegylation on pharmaceuticals. Nat Rev Drug Discov 2003; 3:214-221.
107. Guichard M-J, Leal T, Vanbever R. PEGylation an approach for improving the pulmonary delivery of biopharmaceuticals. Curr Opin Colloid Interface Sci 2017; 31:43-50.

108. Cantin AM, Woods DE, Cloutier D, Dufour EK, Leduc R. Polyethylene glycol conjugation at Cys 232 prolongs halflife of $\alpha 1$ proteinase inhibitor. Am J Respir Cell Mol Biol 2002; 27:659-665.

109. McLeod VM, Chan LJ, Ryan GM, Porter CJ, Kaminskas LM, et al. Optimal PEGylation can improve the exposure of interferon in the lungs following pulmonary administration. J Pharm Sci 2015; 104:1421-1430.

110. Koussoroplis SJ, Paulissen G, Tyteca D, Goldansaz H, Todoroff J, Barilly C, Uyttenhove C, Van Snick J, Cataldo DD, Vanbever R. PEGylation of antibody fragments greatly increases their local residence time following delivery to the respiratory tract. J Control Release 2014; 187:91-100.

111. Patil HP, Freches D, Karmani L, Duncan GA, Ucakar B, Suk JS, Hanes J, Gallez B, Vanbever R. Fate of PEGylated antibody fragments following delivery to the lungs: influence of delivery site, PEG size and lung inflammation. J Control Release 2018; 272:62-71.

112. Pleasants RA, Hess DR. Areosol delivery devices for obstructive lung diseases. Respir Care 2018; 16:708-733.

113. Lamche H, Meade C, Zierenberg B, Reimholz R. Process for nebulizing aqueous compositions containing highly concentrated insulin. U.S. Patent US20030064032A1. Issued 6. Nov. 2002.

114. Morales JO, Fathe KR, Brunaugh A, Ferrati S, Li S, Montenegro-Nicolini $\mathrm{M}$, et al. Challenges and future prospects for the delivery of biologics: oral mucosal, pulmonary, and transdermal routes. AAPS J 2017; 19(3):652-668.

115. Deller D, Thipphawong B, Otulana B, Caplan D, Ericson L, Milgram J, Okikawa J, Bowman QCM. Bolus inhalation of rhDNase with the AERx system in subjects with cystic fibrosis. J Aerosol Med 2003; 16:175-182.

116. Sangwan S, Agosti JM, Bauer LA, Otulana BA, Morishige RJ, Cipolla DC, Blanchard JD, Smaldone GC. Aerosolized protein delivery in asthma: gamma camera analysis of regional deposition and perfusion. J Aerosol Med 2001; 14:185-195.

117. Hollander PA, Blonde L, Rowe R, Mehta AE, Milburn JL, Hershon KS, Chiasson J-L, Levin SR. Efficacy and safety of inhaled insulin (exubera) compared with subcutaneous insulin therapy in patients with type 2 diabetes: Results of a 6-month, randomized, comparative trial. Diabetes Care 2004; 27:2356-2362.

118. Colombo RE, Fiorentino C, Dodd LE, Hunsberger S, Haney C, Barrett K, Nabha L, Davey RT, Jr. Olivier KN. A phase 1 randomized, double-blind, placebo-controlled, crossover trial of DAS181 (Fludasefi) in adult subjects with wellcontrolled asthma. BMC Infect Dis 2015; 16:1-10.

119. Syabbalo N. The role of thymic stromal lymphopoietin in the pathogenesis and treatment of severe uncontrolled asthma. J Lung 2021; 2(3):6931.

120. Fahy JV, Cockroft DW, Boulet L-P, Wong HH, Deschesnes F, Davis EE, Ruppel J, Su JQ, Adelman DC. Effects of aerosolized anti-IgE (E25) on airway responses to inhaled allergen in asthmatic subjects. J Respir Crit Care Med 1999; 160:1023-1027.

121. Matschiner G, Huang S, Constant S, Rattenstetter B, Gille H, Hohlbaun AM, Koller B, Keeling D. Fitzgerald M. The discovery and development of AZD1402/PRS-060, an 
inhaled, potent and selective antagonist of IL-4 receptor alpha. Airway Pharmacol Treat 2018; 52:PA1047.

122. Burns I, Fitzgerald MF, Pardali K, Gardiner P, Keeling D, Axelsson L. Jiamg F, Lickliter J, Close D. First-in-human data for the inhaled IL-4R antagonist AZD1402/PRS-060 reveals a promising clinical profile for the treatment of asthma. Am J Respir Crit Care Med 2019; 199:A7476.

123. Freches D, Patil HP, Franco MM, Uyttenhove C, Heywood $\mathrm{S}$, Vanbever R. PEGylation prolongs the pulmonary retention of an anti-IL-17A Fab' antibody fragment after delivery in three different species. Int J Pharm 2017; 521:120-129.

124. Gauvreau G, Hohfeld J, Boulet L-P, Cockcroft D, Davis B, Fitzgerald JM, Korn S, Kornmann O, Leigh R, et al. Late Breaking Abstract - Efficacy of CSJ117 on allergeninduced asthmatic responses in mild atopic asthma patients. Eur Respir J 2020; 56:3690. DOI: 10.1183/13993003.congress-2022.3690.
This work is licensed under Creative Commons Attribution 4.0 License

\section{To Submit Your Article Click Here: Submit Manuscript}

DOI: $10.31579 / 2693-2156 / 035$
Ready to submit your research? Choose Auctores and benefit from:

* fast, convenient online submission

* rigorous peer review by experienced research in your field

* rapid publication on acceptance

* authors retain copyrights

* unique DOI for all articles

* immediate, unrestricted online access

At Auctores, research is always in progress.

Learn more www.auctoresonline.org/journals/journal-of-thoracicdisease-and-cardiothoracic-surgery- 